\title{
RELAÇÕES HÍDRICAS EM SERINGAL NO MUNICÍPIO DE PIRACICABA, SP ${ }^{1}$
}

\author{
M.E.G. MENDES ${ }^{2}$; M.M. VILLAGRA ${ }^{3,6}$; M.D. de SOUZA²; O.O.S. BACCHI ${ }^{4,6}$; \\ K. REICHARDT ${ }^{5,6}$
}

RESUMO: Em um estudo das relações hídricas de um seringal de 5 anos de idade, implantado na região sudeste do Brasil em 1984 são mostradas variaçōes de umidade do solo, potencial da água no solo, distribuição radicular, interceptação de precipitação pluvial e escoamento superficial. Resultados indicam a estreita faixa de retenção de água da terra roxa estruturada e a alta correlação entre as variaçōes de potencial da água no solo e a distribuição radicular. $O$ seringal apresentou um sistema radicular com raizes superficiais $(0-30 \mathrm{~cm})$ se estendendo até a projeção das copas e raízes profundas, atingindo mais de $2,5 \mathrm{~m}$. 0 perfil de solo não apresentou escoamento subsuperficial de água ao longo do declive de $10 \%$, mas apresentou significantes perdas superficiais, chegando a $50 \%$ da chuva em dias com superfície do solo muito úmida. A interceptação média das copas não passou de $5 \%$ da precipitação pluvial.

Descritores: seringueira, distribuição radicular, umidade do solo, potencial da água no solo, runoff, interceptação de chuva.

\section{WATER RELATIONS in A RUBBer-TREe PLANTATION OF PIRACICABA, SP.}

ABSTRACT: A study of water relations of a rubber-tree plantation of 5 years age, established in southeast Brazil in 1984, shows changes in soil water content, soil water potential, root distribution, rainfall interception and runoff. Results show the narrow soil water storage range of "terra roxa estruturada" soil and the high correlation between soil water potential changes and root distribution. The plantation presents a root system with superficial roots $(0-30 \mathrm{~cm})$ which extends to the projection of the tree tops, and deeper roots reaching depths greater than $2.5 \mathrm{~m}$. Soil profile did not present sub-surface runoff along the $10 \%$ slope but presented significant surface losses reaching $50 \%$ of rainfall in days when soil surface was very wet. Tree top rainfall interception did not exceed $5 \%$ of the rainfall.

Key Words: rubber-tree, root distribution, soil water content, soil water interception.

\section{INTRODUÇÃO}

A seringueira (Hevea brasiliensis Muell. Arg.), planta nativa da Amazônia, foi responsável no início do século XX pelo abastecimento de cem por cento da borracha natural utilizada no mundo e nesta região sempre se mostrou mais viável como uma cultura extrativa. Recentemente os trabalhos de zoneamento da heveicultura no Brasil demonstraram seu enorme potencial de produção em regiões ecologicamente aptas denominadas não tradicionais, de vários estados do centro-sul, como São Paulo, Minas Gerais e Mato Grosso do Sul. Como consequência nas últimas décadas, a cultura da seringueira teve um desenvolvimento bastante acentuado no Estado de São Paulo (SIMPÓSIO SOBRE A CULTURA DA SERINGUEIRA NO ESTADO DE SÃO PAULO, 1986).

Com base na necessidade de elevada pressão de turgescência nos vasos laticíferos, para que se

\footnotetext{
${ }^{1}$ Trabalho realizado com auxílio parcial CNPq/CAPES.

${ }^{2}$ Aluno do Curso de Pós-Graduação em Solos e Nutrição de Plantas da ESALQ/USP, CEP 13418-900 Piracicaba,SP.

${ }^{3}$ Aluna do Curso de Pós-Graduação em Ciência do Solo da Universidade de Gent, Bélgica, B-9000 Gent, Belgium.

${ }^{4}$ Pesquisador da Seção de Física de Solos do CENA. Caixa Postal 96, CEP 13418-900 - Piracicaba,SP.

${ }^{s}$ Professor titular do DFM/ESALQ/USP, Caixa Postal 9, CEP 13418-900 - Piracicaba, SP e Pesquisador do CENA.

${ }^{6}$ Bolsista do CNPq.
} 
verifique um escoamento de maior volume de látex (BUTTERY \& BOATMAN,1985), definiu-se de um modo geral que, quanto mais uniforme for a distribuição mensal das chuvas maior será a produtividade da seringueira. Isso é realmente válido para locais em que não ocorram enfermidades graves das folhas, causadas por fungos que exigem umidade $e$ temperaturas elevadas para ataques epidêmicos. Uma distribuição pluviométrica sem estação seca definida é boa para a seringueira, mas $\varepsilon$ melhor ainda para $o$ Microcylus ulei, fungo causador do "mal das folhas" $e$ outros agentes infecciosos (CARDOSO e OLIVEIRA, 1971 e CARDOSO, 1980).

A periodicidade térmica e hídrica nas áreas não tradicionais impede o surgimento do "mal das folhas" desde que o reenfolhamento coincida com a estação seca. A despeito das condições edafo-climáticas bastante diferenciadas destas áreas, a seringueira vem se desenvolvendo de modo bastante satisfatório, muito embora ainda exista a necessidade de pesquisas para se chegar ao pleno conhecimento dessa exploração no sudeste do Brasil.

$\mathrm{Em}$ virtude da cultura da seringueira apresentar longo período de imaturidade, bem como adotar sistemas de produção fundamentados em espaçamentos com amplas faixas livres de terra, FANCELLI (1986) evidencia ainda a necessidade do estabelecimento de estratégias que concorram significativamente para a conservação do solo, do armazenamento de água no solo e do uso racional das áreas com culturas intercalares. Procurando colaborar para o esclarecimento destes aspectos, o presente trabalho analisa em detalhe, no período $89 / 91$, as relações hídricas de um seringal implantado em Piracicaba, SP, em 1984.

\section{MATERIAL E MÉTODOS}

O trabalho foi realizado em área experimental da Escola Superior de Agricultura "Luiz de Queiroz", em cultura de seringueira (Hevea brasiliensis Muell Arg.). O seringal formado por parcelas de várias cultivares foi instalado em novembro de 1984, no espaçamento de $7 \mathrm{~m} \times 3 \mathrm{~m}$. Os estudos aqui relatados referem-se à parcela da cultivar IAN 3087 no período de agosto de 1989 até maio de 1991.

A descrição do perfil do solo realizada na parcela do experimento levou à classificação: KANHAPLUDALF ou TYPIC KANDIUDALF, que no sistema brasileiro refere-se à Terra Roxa estruturada. A área em estudo possui declividade de $10 \%$, o perfil é considerado bem drenado do ponto de vista pedológico.
Dentro do talhão de $20 \mathrm{~m} \times 50 \mathrm{~m}$ foram instalados equipamentos para o estudo da dinâmica da água no perfil de solo, da interceptação da chuva pela cultura e do escoamento superficial de água. Para isto foi delimitada uma parcela padrão para a medida do escoamento superficial, de $2 \mathrm{~m} \times 21,5 \mathrm{~m}$, ao longo do maior declive do terreno, totalmente cercada por meio de chapa galvanizada de $30 \mathrm{~cm}$ de altura, sendo $15 \mathrm{~cm}$ introduzidos no solo. Na parte inferior da parcela, uma calha leva a água escorrida a tanques coletores (Figura 1). O escoamento superficial ou runoff ( $R \mathrm{~mm}$ ) foi medido de forma integrada sobre períodos de $24 \mathrm{~h}$, isto é, das 8:00h às 8:00h Seu cálculo foi feito pelo quociente do volume (1) de água coletado nas 24 horas pela área da rampa $\left(\mathrm{m}^{2}\right)$.

O estudo da interceptação da chuva foi feito através de leituras de 10 pluviômetros de área de captação $300 \mathrm{~cm}^{2}$, instalados a $30 \mathrm{~cm}$ da superfície do solo e distribuídos, ao acaso, embaixo das copas e nas entrelinhas. Para efeito de comparação, também foram utilizados os dados de chuva do Posto Meteorologico da ESALQ, localizado a cerca de $300 \mathrm{~m}$ do seringal.

A dinâmica da água no solo foi estudada a partir de observações de umidade e de potencial da água no solo. Para isso foram instalados, dentro da parcela de medida de runoff, sete tubos de alumínio para medida com sonda de nêutrons e sete baterias de tensiômetros com manômetro de mercúrio. A umidade do solo foi medida nas profundidades $25 \mathrm{~cm}, 50 \mathrm{~cm}$, $75 \mathrm{~cm}, 100 \mathrm{~cm}, 125 \mathrm{~cm}$ e $150 \mathrm{~cm}$; o potencial da água no solo nas profundidades $12,5 \mathrm{~cm}, 37,5 \mathrm{~cm}, 62,5 \mathrm{~cm}$, $87,5 \mathrm{~cm}, 112,5 \mathrm{~cm}, 137,5 \mathrm{~cm}$ e $162,5 \mathrm{~cm}$, ambos a partir da superfície do solo. Os tubos de sonda e conjuntos de tensiômetros foram instalados ao longo do maior declive do terreno, espaçados entre si de $2,5 \mathrm{~m}$, como mostra a Figura 1. Devido à declividade de $10 \%$ da rampa, uma profundidade $(z) \mathrm{cm}$ em um dos pontos de observação, corresponde a uma profundidade $(z+25)$ $\mathrm{cm}$ no ponto de observação vizinho à montante, em relação ao plano horizontal que passa por $z$.

As medidas de umidade e de potencial da água foram feitas de forma aleatória, no mínimo quinzenalmente. Em períodos úmidos chegou-se a fazer leituras diárias de potencial da água.

O sistema radicular da seringueira foi observado através de amostragens de trado, cada uma com um volume de 6 litros, de acordo com MONTENEGRO (1960). A separação solo-raiz foi feita com lavagem em peneira de $1,5 \mathrm{~mm}$ de malha. Após secagem em estufa, de $60-70^{\circ} \mathrm{C}$, até peso constante, as raízes foram pesadas e os resultados expressos em termos de porcentagem do total. 


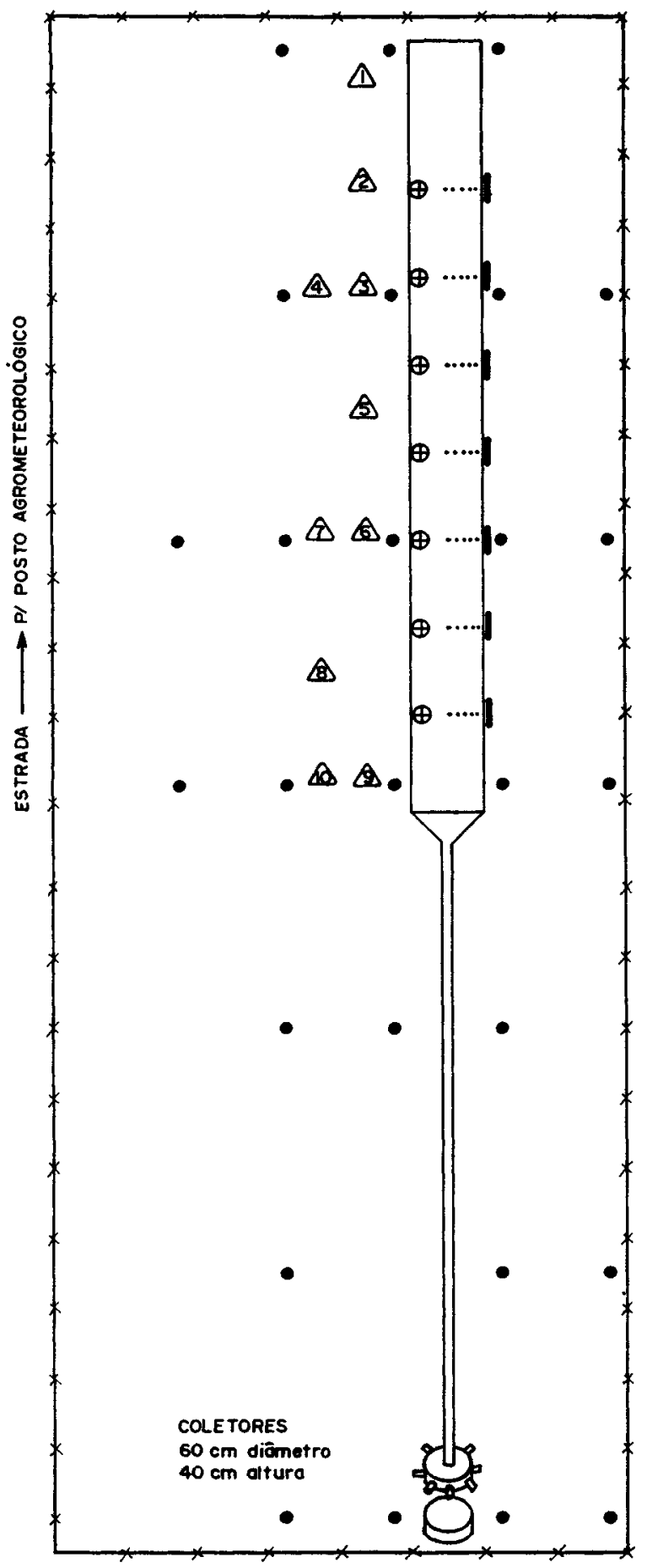

LEGENDA:

A PLUVIŌMETROS

(diometro- $20 \mathrm{~cm}$, alturo- $30 \mathrm{~cm}$ )

๑ tubos p/ ACESSO da sonda de néutrons

- ávores (SERINGUeIRAS)

.... Baterias de tensiómethos

1 manōmetros de meacúpio

Figura 1. Esquema da distribuição dos instrumentos no campo. 


\section{RESULTADOS E DISCUSSÃo}

O solo em estudo apresenta uma faixa estreita de água disponivel e como consequência, os perfis de umidade não variaram de forma significativa de um período de leitura para outro. A Figura 2 mostra os perfis mais úmido e mais seco obtidos durante o período de observação.

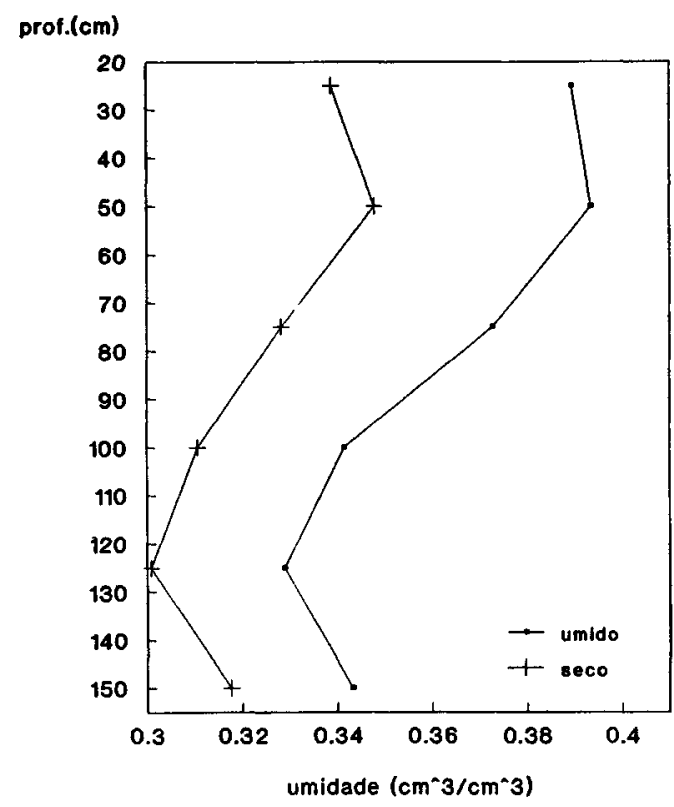

Figura 2 - Variação da umidade em profundidade entre o período mais seco e o mais úmido.

O armazenamento de água na camada 0$150 \mathrm{~cm}$, nas respectivas datas é $528 \mathrm{~mm}$ e $448 \mathrm{~mm}$, resultando uma diferença de apenas $80 \mathrm{~mm}$. Como na época em que foi medido o perfil mais seco a cultura não se apresentava sob stress hídrico, a cultura deve extrair água de camadas mais profundas. Observações do sistema radicular realizadas no local indicaram a presença de raízes até $270 \mathrm{~cm}$, isto é, muito abaixo da camada em estudo $(0-150 \mathrm{~cm})$. As Figuras 3 e 4 mostram distribuições de raízes em torno de uma seringueira próxima à parcela. Nota-se que o maior volume de raízes na entrelinha de plantio, encontra-se entre $160 \mathrm{~cm}$ e $90 \mathrm{~cm}$ do tronco da árvore. Em termos de profundidade, existe um grande volume de raízes na superfície (camada $0-30 \mathrm{~cm}$ ), quantidades: muito pequenas de $30 \mathrm{~cm}$ a $120 \mathrm{~cm}$ e um volume apreciável abaixo de $120 \mathrm{~cm}$, chegando ate $270 \mathrm{~cm}$, ou mais. Ao que parece existem duas regiões de concentração radicular, uma superficial que se aproveita de todas as chuvas, mesmo que pequenas e outra profunda, que garante o suprimento de água nas épocas mais secas.

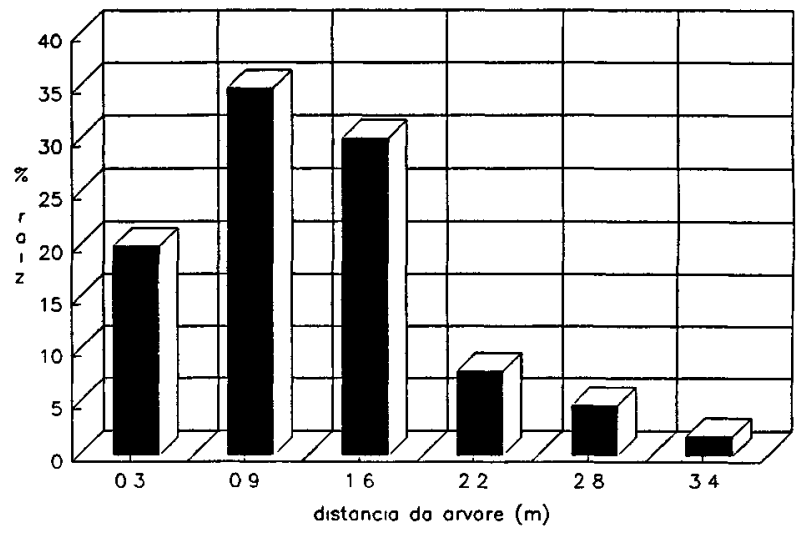

Figura 3 - Raízes de seringueira (em \%) a diferentes distâncias do tronco nas profundidades estudadas.

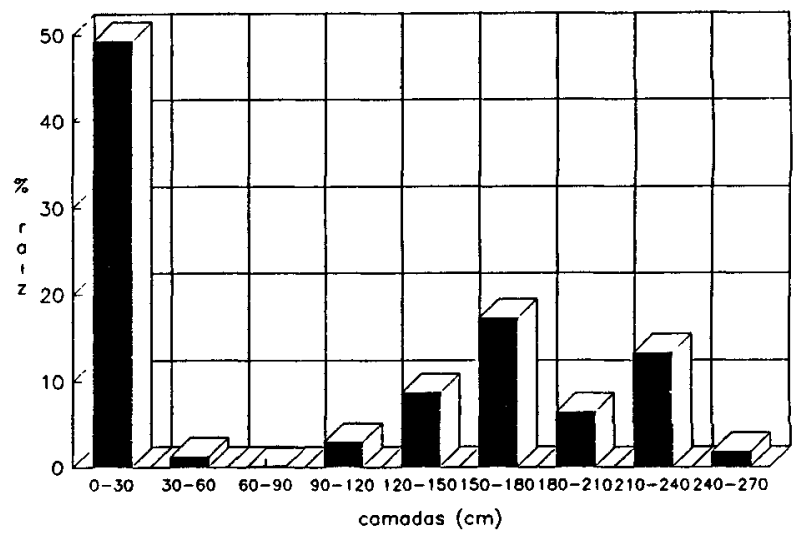

Figura 4 - Raízes de seringueira (em \%) nas diferentes camadas de solo, a 0,80 $\mathrm{m}$ do tronco, na linha de plantio.

As Figuras 5 e 6 mostram a distribuição do potencial total da água no solo em duas épocas distintas, uma seca e outra bastante úmida. $\mathrm{Na}$ época seca vê-se como as linhas de fluxo de água se dirigem para os pontos onde se encontram as árvores. As variaçōes destes potenciais indicam atividade radicular em todo o perfil e estes dados estão em acordo com as distribuições radiculares observadas e indicadas nas Figuras 3 e 4.

A Figura 6, com dados obtidos em um dia chuvoso, precedido de três dias de chuva, mostra os padrões de drenagem do perfil, não mostram deflúvio 
sub-superficial. Para haver fluxos de água no solo ao longo da pendente, há necessidade de uma grande variação da condutividade hidráulica em profundidade. PREVEDELLO (1986) estudou a condutividade hidráulica deste solo e mostrou não haver uma redução pronunciada deste parâmetro para o horizonte $B$ textural, que no local em questão, não é muito evidente. Em períodos muito úmidos, os fluxos de água são portanto verticais e apenas em profundidades maiores do que as estudadas, ao encontrarem camadas menos permeáveis, eles tomam o sentido da declividade do terreno, indo contribuir com a formação do ribeirão na parte mais baixa do terreno.

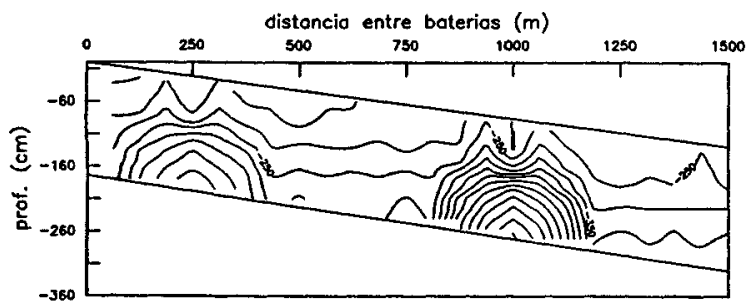

Figura 5 - Distribuição do potencial total da água no solo no período seco.

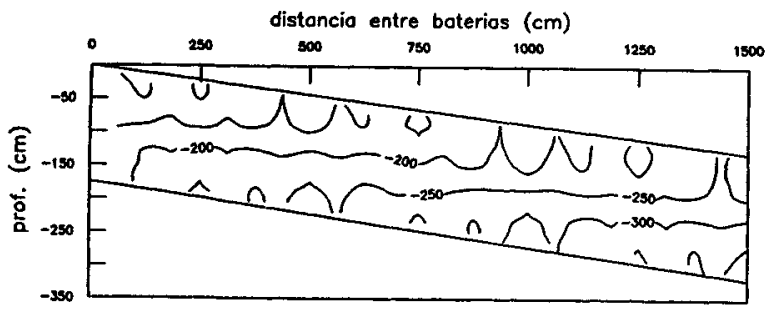

Figura 6 - Distribuição do potencial total da água no solo no período chuvoso.

Quanto à interceptação da chuva pelas copas, os dados apresentam uma grande variabilidade para cada chuva, como uma consequência da posição relativa de cada pluviômetro dentro da parcela. A variabilidade dos dados porém não é consistente no tempo, isto é, pluviômetros embaixo das copas não apresentam sistematicamente maior ou menor volume de água. Apesar da grande variabilidade para uma chuva, as médias por pluviômetro para todo o período de observação não diferem significativamente entre si.

Como a interceptação da chuva é função de sua intensidade, foi feita uma análise por faixa de intensidade. A Figura 7 mostra as médias, por pluviômetro, por faixa de $10 \mathrm{~mm}$, cobrindo todo período de observação. Vê-se claramente que a variabilidade destas médias não é grande de pluviômetro para pluviômetro. Para um dia de chuva porém, o coeficiente de variação pode alcançar $50 \%$.

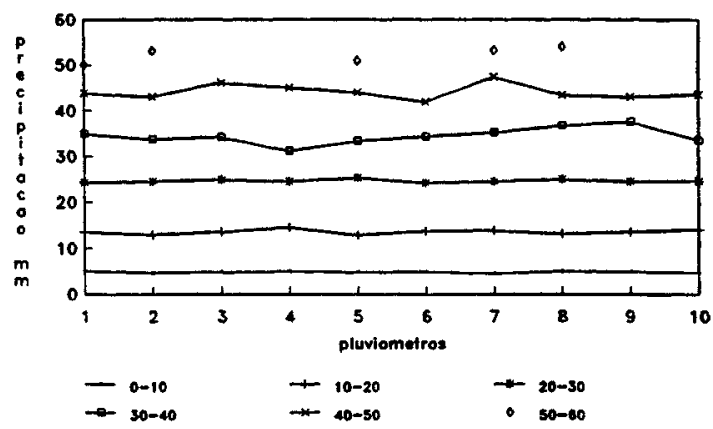

Figura 7 - Compara da precipita média por pluviômetro e por intervalos de $10 \mathrm{~mm}$.

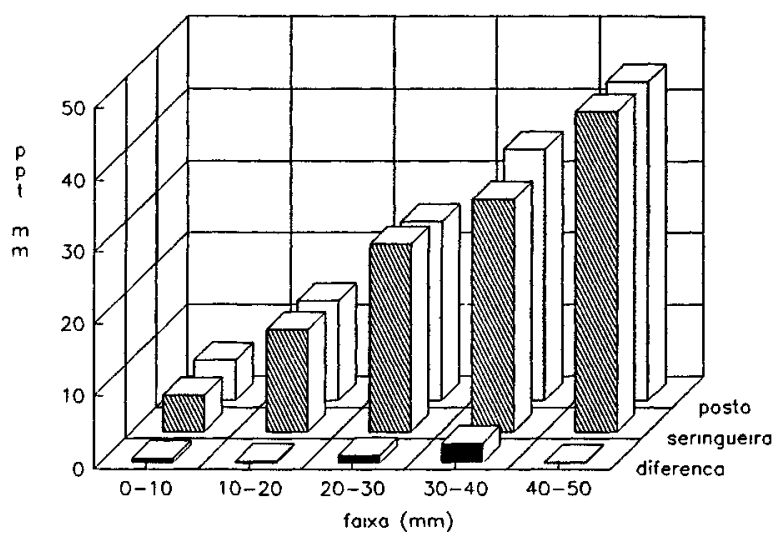

Figura 8 - Comparação da precipitação média por faixa entre o posto meteorológico e o seringal.

A comparação dos valores médios dos 10 pluviômetros do seringal com o valor do pluviômetro do Posto Meteorológico é feita através da Figura 8, também por faixas de intensidade. Pela média geral, a precipitação no Posto Meteorológico é 5\% maior que no seringal, sendo este um valor médio indicativo da interceptação. Por faixas, a Figura 8 mostra que as chuvas de $10-20 \mathrm{~mm}, 20-30 \mathrm{~mm}$ e $40-50 \mathrm{~mm}$ foram maiores no seringal. Chuvas de $30-40 \mathrm{~mm}$ foram bem maiores no Posto Meteorológico e, como consequência, no total, as chuvas no Posto Meteorológico foram maiores que no seringal.

Quanto ao escoamento superficial (runoff) a variabilidade dos dados também é elevada. Como $e$ sabido, a umidade do solo na superfície, antes da chuva, exerce uma influência grande no total de água 
QUADRO 1. Precipitação (ppt), runoff c percentagem de ppt perdida como runoff.

\begin{tabular}{|c|c|c|c|c|c|c|c|}
\hline dia & $\begin{array}{l}\mathrm{ppt} \\
(\mathrm{mm})\end{array}$ & $\begin{array}{l}\text { runoff } \\
(\mathrm{mm})\end{array}$ & $\begin{array}{c}\text { perda } \\
(\%)\end{array}$ & dia & $\begin{array}{c}\mathrm{ppt} \\
(\mathrm{mm})\end{array}$ & $\begin{array}{l}\text { runoff } \\
(\mathrm{mm})\end{array}$ & $\begin{array}{c}\text { perda } \\
(\%)\end{array}$ \\
\hline $07 / 07 / 90$ & 26.08 & 2.36 & 9.05 & $05 / 02$ & 17.72 & 5.05 & 28.50 \\
\hline $19 / 07 / 90$ & 49.30 & 5.00 & 10.14 & $08 / 02$ & 17.40 & 2.77 & 15.92 \\
\hline $24 / 07 / 90$ & 12.14 & 0.36 & 2.97 & $09 / 02$ & 28.92 & 16.02 & 55.39 \\
\hline $25 / 07 / 90$ & 8.24 & 0.79 & 9.59 & $10 / 02$ & 10.58 & 2.51 & 23.72 \\
\hline $20 / 08 / 90$ & 17.16 & 0.06 & 0.35 & $19 / 02$ & 5.96 & 0.37 & 6.21 \\
\hline $14 / 09 / 90$ & 20.08 & 0.25 & 0.83 & $02 / 03$ & 30.65 & 1.16 & 3.78 \\
\hline $19 / 10 / 90$ & 31.44 & 0.20 & 0.64 & $03 / 03$ & 45.74 & 23.67 & 51.75 \\
\hline $21 / 10 / 90$ & 40.56 & 5.37 & 13.24 & $04 / 03$ & 25.50 & 6.39 & 25.06 \\
\hline $02 / 11 / 90$ & 18.49 & 0.07 & 0.38 & $06 / 03$ & 43.92 & 22.96 & 52.28 \\
\hline $03 / 11 / 90$ & 13.06 & 0.87 & 6.66 & $07 / 03$ & 8.46 & 0.86 & 10.17 \\
\hline $27 / 11 / 90$ & 11.04 & 0.39 & 3.53 & $08 / 03$ & 9.08 & 4.40 & 48.46 \\
\hline $05 / 01 / 91$ & 9.85 & 0.15 & 1.52 & $20 / 03$ & 6.46 & 1.36 & 21.05 \\
\hline $12 / 01 / 91$ & 46.42 & 9.90 & 21.33 & $26 / 03$ & 19.53 & 0.60 & 3.07 \\
\hline $15 / 01 / 91$ & 18.90 & 0.98 & 5.19 & $27 / 03$ & 20.22 & 1.51 & 7.47 \\
\hline $16 / 01 / 91$ & 37.12 & 9.80 & 26.40 & $28 / 03$ & 39.20 & 8.12 & 20.71 \\
\hline $27 / 01 / 91$ & 29.14 & 0.31 & 1.06 & $29 / 03$ & 28.70 & 4.55 & 15.85 \\
\hline $28 / 01 / 91$ & 10.22 & 1.48 & 14.48 & $30 / 03$ & 7.54 & 0.16 & 2.12 \\
\hline $29 / 01 / 91$ & 9.10 & 1.06 & 11.65 & $31 / 03$ & 12.41 & 3.79 & 30.54 \\
\hline $02 / 02 / 91$ & 40.55 & 18.83 & 46.44 & $14 / 04$ & 10.50 & 0.44 & 4.19 \\
\hline \multirow[t]{2}{*}{$03 / 02 / 91$} & 3.93 & 0.58 & 14.76 & $16 / 04$ & 7.88 & 0.45 & 5.71 \\
\hline & & & & $20 / 04$ & 2.88 & 0.18 & 6.25 \\
\hline
\end{tabular}

infiltrada e perdida no escoamento superficial (HORTON, 1940 e PHILIP, 1957). O Quadro 1 mostra os valores da enxurrada (runoff), da chuva (ppt) e da percentagem runoff'ppt. Nota-se que em média perdeuse $15.6 \%$ da chuva. Porém, considerando apenas dias de chuva precedidos de dias de chuva, nos quais a umidade superficial do solo é alta, estas perdas podem alcançar valores de $50 \%$. Estes valores indicam a necessidade de aplicação de técnicas de conservação de água e solo, o que é feito na área através de terraços espaçados de $25 \mathrm{~m}$.

\section{BIBLIOGRAFIA}

BUTTERY, B.R. \& BOATMAN, S.G. Déficits hídricos e fluxo de látex. In: WATER DEFICITS AND PLANT GROWTH. T.T. Kozlowski (ed.), Academic Press, Nova Iorque. trad. P.C. Hipolito Campinas, Fundação Cargil, 1985. 120p. 
CARDOSO, M. Instruções para a cultura da seringueira. Campinas, Instituto Agronômico, 1980. 42p. (Boletim, 186)

CARDOSO, M. \& OLIVEIRA, J.B. Heveicultura no Estado de São Paulo. Campinas, Plano Nacional da Borracha, 1971. 112p.

FANCELLI, A.L. Culturas intercalares e coberturas vegetais em seringais. In: SIMPÓSIO SOBRE A CULTURA DA SERINGUEIRA NO ESTADO DE SÃO PAULO, 1., Campinas, 1986. Campinas, Fundação Cargill, 1986. p.229-51.

HORTON, R.E. An approach toward a physical interpretation of infiltration-capacity. Soil Sci. Soc. Proc., 4:399-417. 1940.

MONTENEGRO, H.W.S. Contribuição ao estudo do sistema radicular das plantas cítricas. Piracicaba,SP, ESALQ/USP. 1960. 186p.

PHILIP, J.R. The theory of infiltration: 5. The influence of the initial moisture content. Soil Sci., 40:329-39. 1957.

PREVEDELlo, C.L. Teoria do fluxo da água em solos não saturados: novos conceitos e aplicações. Piracicaba,SP, ESALQ/USP. 1987. 264p. Tese de Doutorado.

SIMPÓSIO SOBRE CULTURA DA SERINGUEIRA NO ESTADO DE SÃo PAULO, 1., Campinas, 1986. Campinas, Fundação Cargil, 1986. 333p. 